\title{
Coronavirus Environment vs Socio-Economic and Demographic Problems Followed: A Sociological Appraisal
}

\author{
Mohammad Taghi Sheykhi \\ Professor Emeritus of Sociology, Alzahra University, Tehran, Iran \\ mtshykhi@alzahra.ac.ir
}

\section{Abstract}

The paper searches the cause and effect impacts of the newlyfound Coronavirus. The word "Corona" is currently used by all the people ( 7.7 billion) over the age of at least 3. The unprecedented disease is reflecting a large number of effects infecting and killing many people of the rich and the poor. The new phenomenon is continuing rapidly. It brings about recessions and closures in many businesses, and laying off many employees and workers, and that has created income and security problems for the families. The new environment has imprisoned families inside homes disrupting them from the normal and regular interactions. Such people are getting frustrated indoors. The people confined at home are usually exposed and vulnerable to psychological disorders. Almost all those at school age, are banned to attend schools and higher educational institutions at all levels. So, the educational institution is also losing a lot. The new phenomenon needs sociological appraisal from various viewpoints. What is currently happening, will create problems in post-Corona age. One of the problems that will demographically impact the world nations is "migration". Many people of the poor countries will move to more developed countries where they hope to earn their living. So, social demographers need to mind the future scenario. Poor economies will not easily be able to rehabilitate and reconstruct themselves. That is why a large migration wave will be quite likely to occur. Similarly, many countries will face increasing child labor and street children because of shortage of employment for the adults. The method of research used in the present research is of qualitative type--collecting the data through library resources and other media. Findings prove that everybody is exposed to being affected, infected and killed through the Coronavirus.
Keywords

Coronavirus migration; recession; child labor, social demography

\section{Introduction}

The pandemic of newly-emerged coronavirus is observed almost everywhere in the world. The new virus has surprised all people in every country from top to bottom. All the means available have been used to control it, but yet increasing number of people are reported dead every day. The virus is changing every norm and value in different countries. All the socio-economic frames are being affected because of its deadly risks. Increasing people are currently vulnerable vs the coronavirus. Many (more elderly) lose lives in every corner of the world. So, corona deaths are changing relations in families; changing the real value of natural death, and surprisingly making many indifferent to the event of death. Increasing number of aging people who really need each other in old age, lose a spouse that is a great loss in the rest of their lives. Many marriage traditions are suspended and do 
not take place in due time. Coronavirus has also declined many deals and businesses leading to unemployment for an increasing number of people. The scenario is also leading to stressful deliveries and child bearing. Sociologically speaking, the phenomenon is facing a shortage of medical staff. Such a vacuum has contributed to the call back of many retired doctors and nurses to serve their previous jobs. Similarly, lack of beds in hospitals has entailed not admitting many regular patients in need of treatment. Likewise, many medical staff while highly vulnerable against the corona infection, in some cases, they die by the virus.

\section{Research Methods}

The method used in preparing the present article is of qualitative type. In that, various paradigms have been used to find out the necessary facts and figures on coronavirus. Qualitative research as an accepted method of inquiry is well used in sociological investigations. Though coronavirus issue is widely broadcast on different media, and people are objectively involved with that. Data on the issue is ever changing as it a pandemic and constantly diffusing worldwide. In current research, the researcher tried to access the most relevant sources to find the most relevant data to build the literature required. The data fed in the present article is hopefully reliable. The researcher hopes other sociologists will enter the issue, and propose constructive guidelines to calm and improve the present situation. Though literature on the issue not limited, the author tried to investigate many different resources in order to elicit the necessary information to build up the text.

\section{Discussion}

\subsection{Coronavirus vs Migration}

Migration as a demographic event happens when and where there is a work stress. So, after the defeat of Coronavirus, the weaker countries will not be in a position to provide jobs for those 15 years old and over. By then, increasing job seekers will move to the developed countries in search of jobs. Such migrations will take place for the sake of social mobility, economic achievements, familial relations, educational attainments among the members of young generations etc.

But, as social demographers predict, granting refugee status would also be controversial. Due to antipathy towards the admission of migrants and refugees, complicated situation will emerge. So, due prediction should be made. Anti-immigration mobilization and attitudes are what the world will witness in post-Coronavirus age. However, the Coronavirushit countries of the developing world will also lack young man power to build and develop their countries. Though the global world was created before, further cultural merge will take place. The Internet and social media have facilitated and created venues for migration, and at the same time, they could cause anti-immigrant perspectives. However, if harsh immigrant policies are adopted, confusions and conflicts will emerge.

Moreover, Coronavirus has changed attitudes toward natural death, changed family relations, loneliness, changed attitudes toward marriage. It has also changed business relations, disrupted deals, contracts and the like which all will lead to migration then after.

\subsection{Natural Death vs Covid-19 Death}

The increasing and sudden deaths occurring because of coronavirus have decreased the value weight of natural deaths. People have almost created demotions towards the natural deaths in themselves. The survivors are not much affected and worried after the death of a 
family member as compared with the past patterns. So, a heavier vehicle has lowered the importance of the natural one. At the time of coronavirus, every individual thinks he/she will soon be infected and die by a sudden contact. So, everything is unstable at this critical time. However, during the non-coronavirus time, people used to take a lesson from the death of the deaths of their nears and dears, but the new type of deaths do not leave behind any such lessons.

At the time of pandemic deaths, empathy and sympathy decrease, and many people just think of their very immediate nears. The new current phenomenon is a new experience for many people and nations since 1950 at least. Many of the existing people have not seen even cholera and malaria epidemics. In the past, even at the time of any epidemie outbreak, as there was not any motorized commuting, it only vanished the people of a certain location, and the spread was not as such.

Table 1. Selected Coronavirus Countries by Total Cases and Total Deaths 28 March and 11 April, 2020

\begin{tabular}{|c|c|c|c|c|}
\hline \multirow{2}{*}{ Country } & Total Cases & Total Cases & Total Deaths & Total Deaths \\
\cline { 2 - 5 } & 28-Mar-2020 & 11-Apr-2020 & 28-Mar-2020 & 11-Apr-2020 \\
\hline World & 621.592 & 1.773 .301 & 28.791 & 108.447 \\
\hline USA & 105.161 & 529.343 & 1.722 & 20.466 \\
\hline Italy & 86.498 & 152.271 & 9.134 & 19.468 \\
\hline China & 81.394 & 81.953 & 3.295 & 3.339 \\
\hline Spain & 72.248 & 163.027 & 5.812 & 16.606 \\
\hline Germany & 53.340 & 127.288 & 399 & 2.736 \\
\hline France & 32.964 & 129.654 & 1.995 & 13.832 \\
\hline UK & 17.089 & 78.991 & 1.019 & 9.875 \\
\hline Switzerland & 13.377 & 25.107 & 242 & 1.036 \\
\hline Netherlands & 9.762 & 24.413 & 639 & 2.643 \\
\hline Canada & 4.757 & 23.318 & 55 & 653 \\
\hline Australia & 3.635 & 6.303 & 14 & 56 \\
\hline Japan & 1.499 & 6.005 & 17 & 99 \\
\hline South Africa & 1.170 & 2.028 & 01 & 25 \\
\hline India & 933 & 8.446 & 20 & 288 \\
\hline
\end{tabular}

Source: World meter Coronavirus, Population. March 28 and 11 April, 2020.

\subsection{Appearance of Lonely Men and Women}

Coronavirus while killing one partner, the other remaining party feels lonely and isolated. He/she has to support the family later in terms of economy, finance, emotions etc. In the post-Corona era, the countries would be able to have survivors under their supportive umbrella. As it mostly happens to elder people, those who remain alive have a large number of problems including income, care, food preparation, sympathy, feeling of isolation, shortage of family integration etc. Such a situation would be more difficult for women than men who are Corona-hit. While men can usually marry after losing spouse, women usually do not get such an opportunity. Such a poverty would be there more in traditional developing countries rather than the modern developed countries where there are fewer stigmas and socio-cultural taboos. In developing countries where not many elder people are insured, and do not often receive regular pensions, Coronavirus has the worse impacts on the families of the Corona-infected people. 
Those infected by dementia or Alzheimer's disease will be in harder situation at the time of Coronavirus. They won't be able to keep aside, or remain at home like other people. Moreover, if a spouse of one of them dies by Coronavirus, there will not be a close care-giver to provide help and services to the one survived. So, such patients will not have any close family member to monitor them. People with Alzheimer's disease may forget to wash their hands, or take other recommended precautions to prevent the illness/Coronavirus. Similarly, COVID-19 may worsen cognitive impairment due to dementia.

\subsection{Suspension of Marriages}

Coronavirus risks have caused many marriages to be postponed, and in many cases downsized. Developing countries such as India, Pakistan, Bangladesh etc. with large populations and rich traditions, usually have increasing marriage ceremonies and parties for many days. But, many of them have been deferred to control and prevent the immediate disease. Such a postponement creates problems and losses for the families and the people concerned. In many cases the would-be marriages are annulled. However, despite the Western world where cohabitation is a social norm, marriage industry must actively take place in time in developing countries. Many planned weddings for a year are suspended or even cancelled/divorced as happened in some Chinese cases. It is even worrying for the Western world too, to cancel many decided plans, cancel or defer any marriage occasions. Because of Coronavirus risk, almost all marriage halls have remained closed in countries like India and Pakistan. According to the details, a nine-member family attending a marriage ceremony were infected by the deadly Virus (Web Desk, Mar 21, 2020). So, through the appearance of Coronavirus threat, increasing trips are halted and cancelled.

\subsection{Deals and Businesses}

Coronavirus cause many businesses to decline or lock down. Cinemas, restaurants, halls for ceremonies, increasing shops and stores are among the major businesses closed. Such closures have contributed to the unemployment of a large number of workers, So, such an increasing unemployed people affect a large number of families; their access to food items, basic needs, para-educational means etc. Many dealers and small business men and women too, have lost, or may lose their jobs. Such hard times severely impact their careers, their spiritual norms and values.

Similarly, closure of educational institutions and universities has kept backward students and the scientific development in different areas. Though many educational institutions have switched on online system of educational transfer, yet it is not successful for many lecturers and students in many fields of education.

However, thousands of educational institutions across the world are currently remaining closed (Global Citizen, 2020). In countries like China pupils are learning through intimate live video chats, while others are tapping into the "broadcast of primary school lessons on public television". China has also created a "cloud learning program" that teaches its national curriculum.

Because of closures, many disadvantaged students are being deprived to get the free school meals. Similarly, under such circumstances, many children in certain nations can also be at the risk of "child marriage" and "child labor".

\subsection{Stressfull Child Birth}

Coronavirus patients engaging increasing hospital beds has negatively impacted the would-be mothers across the world. Medical facilities which are widely used by the Corona 
patients have weakened the chance of those who want to urgently use the hospital facilities. Coronavirus impact is wide and multi-dimensional, and the result of which will be declared later.

Child birth process is usually a complicated processing birth to a baby Preterm, Premature, Labor that does not progress, Abnormal heart rate of the baby, Perineal tears, Excessive bleeding and many more are the problems needing proper and in place hospitalization.

Similarly, some women have herpes after delivery which really needs hospital attention for both; the mother and the newborn infant (medline plus, 2020). All such complications need nursing and hospital services. During the Coronavirus emergency many such medical urgencies are denied. During pregnancy, some common cold or a skin infection may appear. Though they may not cause serious problems, yet it needs medical attention, care, and treatment. Preterm births sometimes lead to low birth weight that needs immediate and proper protection and treatment. So, shortage of hospital arrangements would endanger the life of the newborn infant, followed by psychological problem/inconvenience for the mother.

\subsection{Shortage of Hospital Beds}

The outbreak of Coronavirus has shortened the hospital beds for the ordinary patients. Hospital-beds shortages are there even in developed countries in these days. Many nonCoronavirus patients cannot be admitted into hospitals for ordinary treatments. For poor countries, ICU beds are difficult expenses. Hospitals can manage their own hospital bed capacity. Shortage of capacity in care units is well felt with special reference to the developing countries. Lack of bed availability, drug shortages and many more is well faced vs the Coronavirus appearance in all countries. People in-doors for protection and precautions also lead to psychological difficulties for many of the families concerned. Around the world, every health care system is struggling with rising costs and ... These pressures are mainly focused on the arriving patients. Therefore, families must take care not to lose their health and well-being (New York Times, 2020).

Countries like Italy with a widespread Coronavirus patients, and one-in-five being a cigarette smoker, the scenario has created complicated problems. Overall, the shortage of hospital beds is well realized. Unfortunately, many developing countries are in lack of budget to increase their strategic plans for health service provisions. Priority is given according to a cluster of factors including need, emergencies, and patient volume. In addition, capacity building and strengthening is quite vital for the improvement of hospital services and treatment of Coronavirus (BMC Health Services Research, 2006).

\subsection{Overwork of the Medical Staff}

Since the outbreak of Coronavirus, medical doctors, nurses, and other staff have roundthe-clock been busy with checking and treatment of virus patients. They have not had leave, holidays and the like. They tirelessly work, and some of them even die because of contacts and infections. In China, while 3400 healthcare workers got Coronavirus, 13 healthcare workers died because of that (Holly Secon, March 4, 2020). Other countries face such problems and deaths too. Medical staff are really exposed to death threats. Some of such staff had postponed weddings to treat the Corona patients. Similarly, 93 healthcare workers in California who came into contact with one patient, before the patient was diagnosed, were put under quarantine or isolation for 14 days.

The United States being the epicenter of global pandemic, reportedly on 26-Mar-2020 had more than 82000 positive infected patients of, and surprisingly China, Spain and Italy 
are the hardest-hit countries vs the Coronavirus (Newsletters.cnn.com, March27, 2020). Similarly, as reported on 28-Mar-2020, Italy had the toll of more than a death every 2 minutes (BBC March 28, 2020). Spain's death toll while tops China's, the number of Coronavirus infected has been reported people there is reported 57,521 patients/cases on 26Mar-2020. Also, the number of death toll in Italy has been reported 9,134 on 26-Mar-2020 (Al Jazeera, 2020).

During the crisis of Coronavirus, many hardworking doctors are facing shortage of equipment, proper masks and protective body suits. In China, because of shortages, some doctors had to wear diapers to avoid having to take off the equipment and make it last longer in Wuhan, China (Japantimes, 2020). Socio-demographically speaking, Coronavirus mostly killing older people, much of the high-experienced and skilled labor capital evacuates. Such pandemic challenges could not be easily compensated for (IUSSP, 2020).

\section{Conclusion}

Coronavirus as a never-thought-before phenomenon has surrounded all countries of the world, and the hots pot of which is taking sacrifices at global level; poor and rich, high ranking, low ranking, educated and uneducated, but more the elderly people. The mercy-less virus is targeting all the countries, causing closures, recessions, poverty, and increasing challenges of all sorts in quality and quantity. Coronavirus is paralyzing tourism, economies, productions, scientific development etc. Coronavirus has also impacted natural death patterns too in many countries. The new phenomenon has led to the appearance of loneliness of many men and women across the world after the death of one spouse. Increasing labor force has been laid off in many countries. Similarly, many marriages and weddings have been postponed or cancelled especially in developing countries such as Bangladesh and India. Due to Coronavirus, increasing number of businesses and trade deals have ceased or slowed. Families also at home and in confinement get disturbed and psychologically impaired. Coronavirus has also created difficulties and challenges for child birth. The operation has become highly stressful, with a great shortage of arrangements in many cases. Another problem well sensed is the lack of hospital beds; the difficulty to get into hospitals with the threats involved. Another difficulty emerged because of the Virus diffusion and outbreak, is the overwork of the medical staff, and the burden they should tolerate.

\section{References}

Al Jazeera, March 23, 2020.

BBC, March 28, 2020.

BMC Health Services Research, Open Access, Research Article, October 6, 2006.

Holly Secon, (March 4, 2020), Feature China/ Barcroft MediaVia Getty Images.

Global Citizen, February 27, 2020.

Medline Plus, Medical Encyclopedia, March 23, 2020.

Newsletters.cnn.com, March 27, 2020.

PERN, March 27, 2020.

The japantimes, March 28, 2020.

World meter Coronavirus Population, 2020.

WWW.Newyorktimes.Com, 1/27/2020. 